\title{
Increasing stakeholder engagement for sustainable natural resource management in Southern Sumatra, Indonesia
}

\author{
Sri Lestari ${ }^{*}$, Bondan Winarno ${ }^{1}$, and Bambang T Premono ${ }^{1}$ \\ ${ }^{1}$ Environment and Forestry Research Development Institute of Palembang \\ Ministry of Environment and Forestry, Jl. Kol. H. Burlian Km 6.5 Puntikayu Palembang \\ South Sumatra, Indonesia.
}

\begin{abstract}
Degradation of natural resources in various areas of Indonesia requires serious attention and action to prevent further damage. This research was descriptive qualitative research, presented data and evidences from two research projects which engage stakeholders to participate in natural resources management in Southern Sumatra. Our finding proved that providing clear information to the stakeholders about the goals to be achieved in natural resource management activities is the most important thing. Furthermore, a detailed description of what stakeholders could do to participate, convincing the stakeholders that they can participate easily and their role is very important in managing this natural resource were also crucial. Other significant aspects were updating information about what has been done, how the results are, also what things are still needed to do in order to reach the goal. Stakeholders will actively participate in natural resource management activities if they know clearly the objectives to be achieved. One of these objectives must be directly or indirectly related to the interests of these stakeholders and provide benefits both tangible and or non-tangible to them. Equity, trust, and learning were needed throughout the process of achieving goals.
\end{abstract}

\section{Introduction}

Sustainable natural resources management is carried out to maintain the sustainability and availability of natural resources themselves and subsequently can be utilized to increase the welfare of the community. Natural resources is common property that has two main characteristics, that are excludability and rivalry (subtractibility)[1]. Since natural resource is excludable, then it is very difficult to limit the access of other parties to the resources. Moreover, once certain actor utilizes the resources it will reduce the availability of the resources for other parties because natural resource is subtractibility [2]. Forest and land degradation that occurs in various regions of Indonesia threatens the sustainability of human life, because the destruction of natural resources can lead to disasters that not only endanger the sustainability of the resources but also the existence of people in it.

\footnotetext{
${ }^{*}$ Corresponding author: lestari@iuj.ac.jp
} 
The involvement and cooperation of several stakeholders both directly and indirectly related to natural resources is needed so that the management of natural resources can be carried out sustainably, efficiently, and effectively. The engagement of stakeholders in sustainable natural resource management is expected to be able to support efforts to protect and preserve natural resources in the nature, since environmental problems are complex, uncertain, and affect several parties [3].

Stakeholders are "person, groups or institutions with interests in policy, program or projects" [4]. Additionally, Freeman (1984) in [5] explained that stakeholders are "any group or individual who is affected by or can affect the achievement of an organization's objectives". More specific, [6] concluded that "Stakeholder is individuals, organizations or communities that have a direct interest in the process and outcome of a project, research, or policy endeavor." Moreover they also mentioned that stakeholder engagement as "An iterative process of actively soliciting the knowledge, experience, judgment and values of individuals selected to represent a broad range of direct interests in a particular issue, for the dual purposes of creating a shared understanding and making relevant, transparent and effective decisions". The engagement of stakeholder is important to the success of any program or projects. Each stakeholder has their own perspective about the research projects itself. In the natural resource management context, stakeholder engagement refers to the participation of stakeholders in planning or decision making efforts hence their knowledge and values can be integrated to support those planning or decision making [7]. Furthermore, [7] also mentioned that effective stakeholder engagement could obtain better decision making, increased social learning, and clearer communication between stakeholder involved. In addition, when the project has ended, implementation of the results or scale up of project results will be easier to carry out if there is support and involvement of various stakeholders.

There are some benefits and challenges of stakeholder engagement [8], the benefits were: establishing credibility, anticipating controversy, ensuring transparency and accountability, improving relevance, enhancing quality, and increasing dissemination and uptake of finding. These benefits could support the research projects in order to reach the goals. On the other hand, the challenges of stakeholder engagement in natural resource management in certain cases can be an obstacle to overcome. Those challenges are time, training and resources, finding the right stakeholder, balancing multiple inputs, and matching the right stakeholder to the right time in the systematic review process [8]. Therefore, the more numerous and diverse stakeholders involved in sustainable natural resource management, it will require additional time and effort to synergize these stakeholders. Each stakeholder has their own interests, desires, expectations for natural resource management both for themselves and for the environment hence the methods to achieve the goals must also be adjusted. Although the management of natural resources aims to realize the sustainability of resources and the welfare of the community, some people think they can get more benefits for each of them personally.

Every research project activity related to natural resource management requires the support and involvement of various relevant stakeholders, starting from the government, the private sector, NGOs, community organizations, community groups, community leaders, and the community itself, especially those dealing directly with natural resources in their region. During this time the community has access to be able to use natural resources even if only to a certain extent. The community's access is limited by various rules and policies both supportive and limiting so that their activities do not pose a threat to sustainable natural resources. This study aims to observe the process of stakeholder engagement, the importance of stakeholder engagement for the sustainability of natural resources, and identify the implementation strategy to increase stakeholder engagement in natural resource management. 


\section{Research Method}

This research applied descriptive qualitative method to observe stakeholder engagement in natural resources management through socioeconomic research projects. The past socioeconomic research projects that have a primary objective for sustainable natural resources management will be evaluated. Therefore, we can learn and understand the process of stakeholder engagement, the importance of stakeholder engagement in each of the process, the effectiveness of some efforts to increase stakeholder involvement and how this approach is successful so that stakeholders are interested in being involved.

Two socioeconomic research projects will be identified and the details of stakeholder engagement process in these projects will be described. The first research project was "Consercation strategy, cultivation, and business analysis of non timber forest product". This research was carried out in some areas in Southern Sumatra, including South Bengkulu, Kaur district, Sarolangun, Ogan Komering Ulu, Semendo darat Ulu, and Medan during 2015 - 2018. The second research project was paludiculture model based on silvopasture as an alternative of peat restoration that was located in Ogan Komering Ilir (South Sumatra) in 2017. Interview to the stakeholders who involved in the research projects was also employed to deepen the analysis.

\section{Results and discussion}

\subsection{Research projects for sustainable natural resources management in Southern Sumatra}

Stakeholder involvement is one of the main factors in the success of a research project carried out. Several research projects aiming to support sustainable natural resources management either directly or indirectly. Two socioeconomic research projects that in the long term have the main goal to realize sustainable natural resources management were identified in this study. Furthermore, we describe how stakeholder engagement has been carried out during the research project process (Table 1). Finally we evaluate the effectiveness of stakeholder engagement effort of each research project. The first research project is conservation strategy, cultivation and business analysis of non timber forest product. This project has been implemented in 5 (five) district of Southern Sumatra. The purpose of this research project was to conserve and cultivate one of non timber forest products that available in the natural forest i.e. dragon's blood. Due to the existence of these forest products is increasingly scarce, people around the forest have tried to develop and plant dragon's blood on their own land. Many information related to business analysis of dragon's blood was also gather to support the conservation and cultivation strategy. This project was carried out in 2015 - 2018. During this time, dragon's blood is one of the sources of income for people around the forest, because dragon's blood has a high economic value for export purposes.

The next research project was "Paludiculture model based on silvopasture as an alternative of peatland restoration". Paludiculture is sustainable production of agriculture on rewetted peatland [9], whereas silvopasture is one of agroforestry practices that integrating livestock and tree management [10]. Sustainability of peatland and restoring the function of the peatland that at the same time could increase the welfare of the people who live nearby the peatland is one of the research project proposes. Sustainable peatland management will help people to maintain their land so that they can save their livelihood to support their life and future. 


\begin{tabular}{|c|c|c|}
\hline 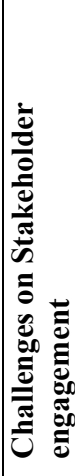 & 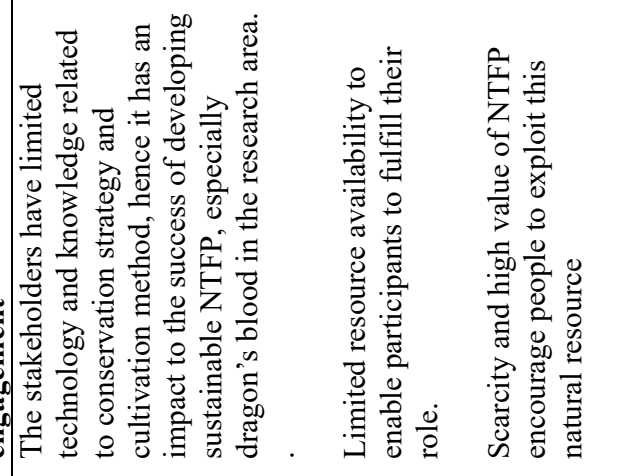 & 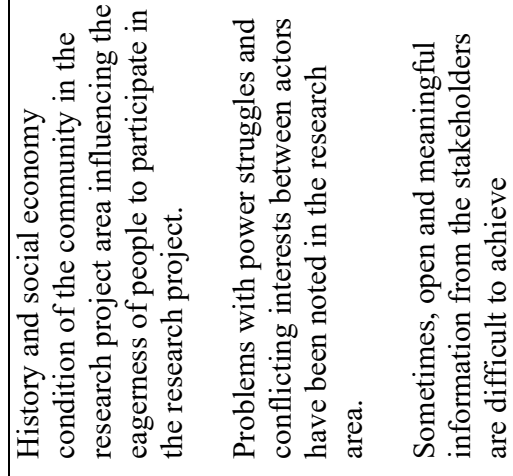 \\
\hline 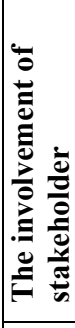 & 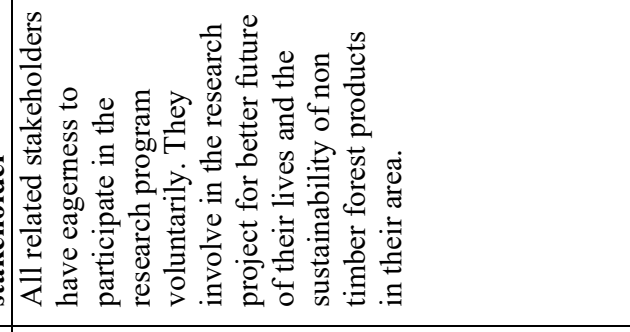 & 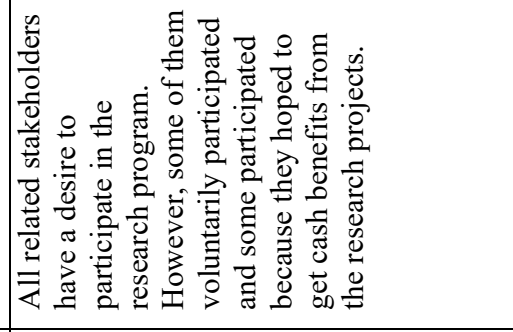 \\
\hline 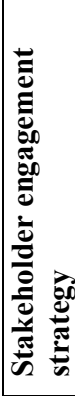 & 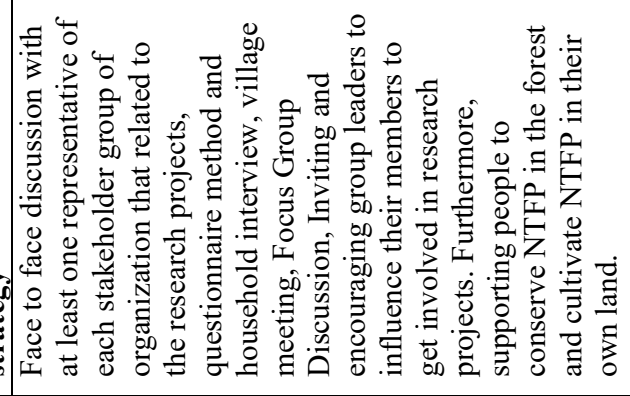 & 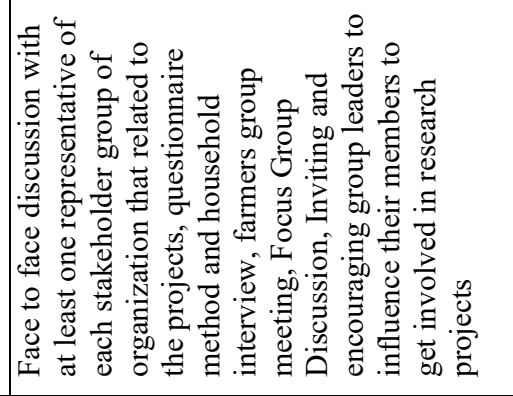 \\
\hline 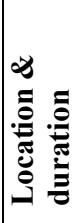 & 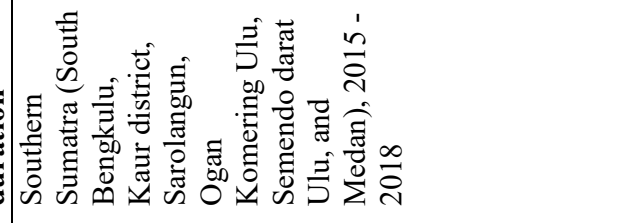 & 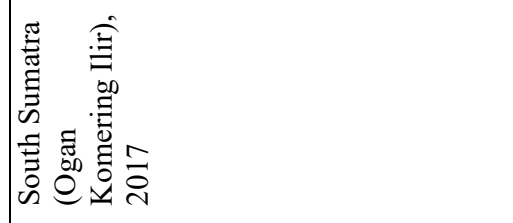 \\
\hline 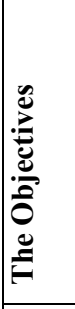 & 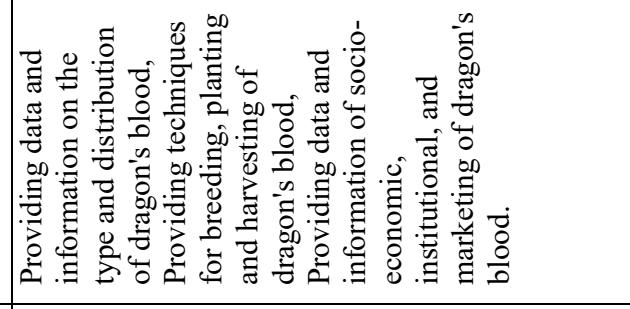 & 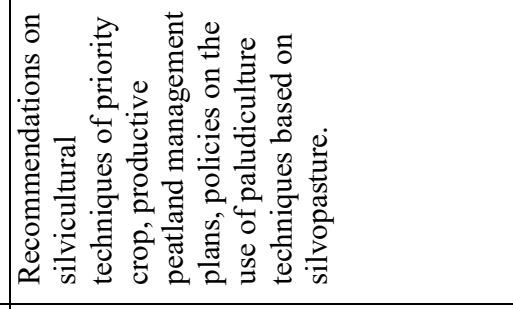 \\
\hline 这 & 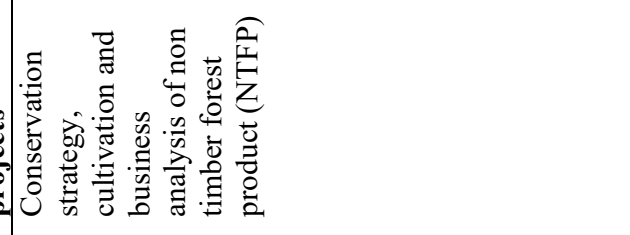 & 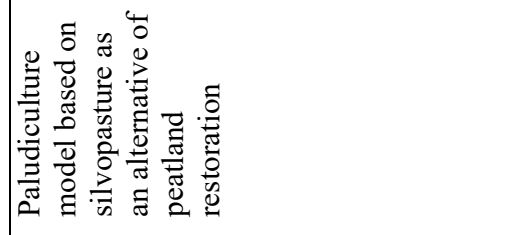 \\
\hline
\end{tabular}




\subsubsection{Case study 1 - Conservation strategy, cultivation, and business analysis of non timber forest product}

Stakeholder engagement strategy in this natural resource management research project was by conducting face to face discussion with at least one representatives of each stakeholder group of organization that related to the research projects. These stakeholders are officers from the ministry of industry in district level (Fig. 1), forest and environmental officers at provincial and district level (Fig. 2), private company, head of the village, the leaders of community group), household interview (Fig. 3) and questionnaire method (Fig.4), village meeting (Fig. 5), Focus Group Discussion (Fig. 6), Inviting and encouraging group leaders to influence their members to get involved in the projects. These face to face interactions and constructive discussions generate beneficial collaborative participatory mechanism in managing natural resource [11].

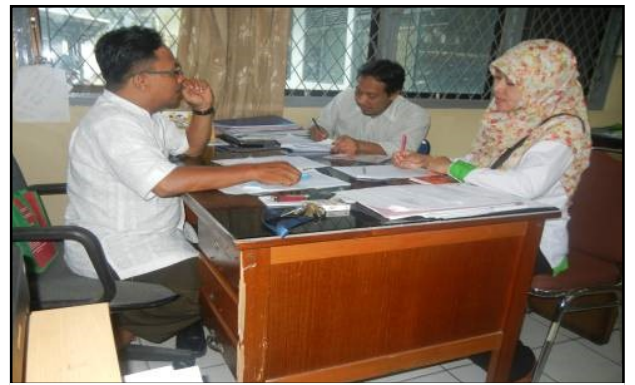

Fig. 1. Discussion with representatives from ministry of industry at the district level

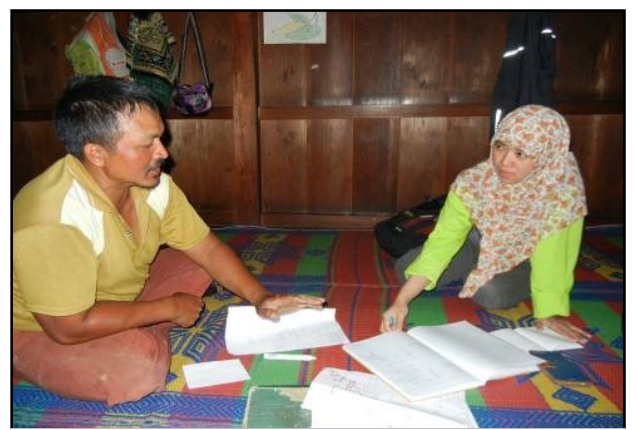

Fig. 3. Interview to household and the community leader

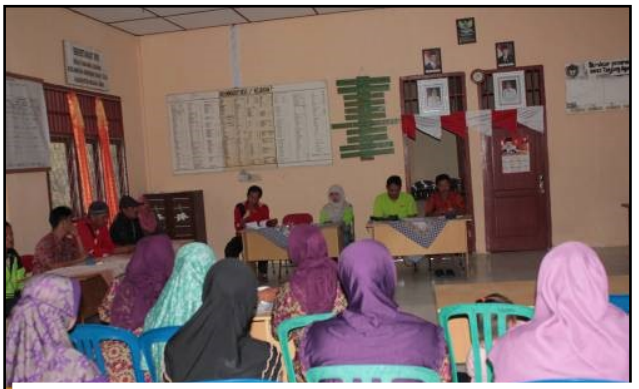

Fig. 5. Village meeting

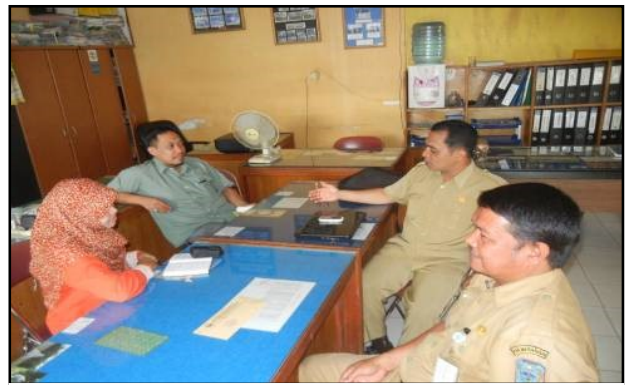

Fig. 2. Discussion with representatives from ministry of forestry at the district level

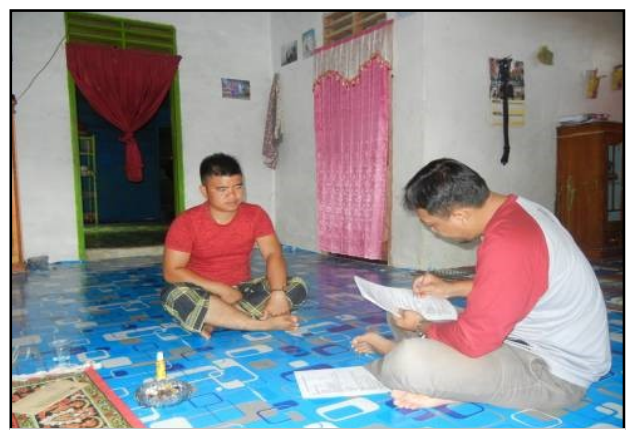

Fig. 4. Questionnaire method

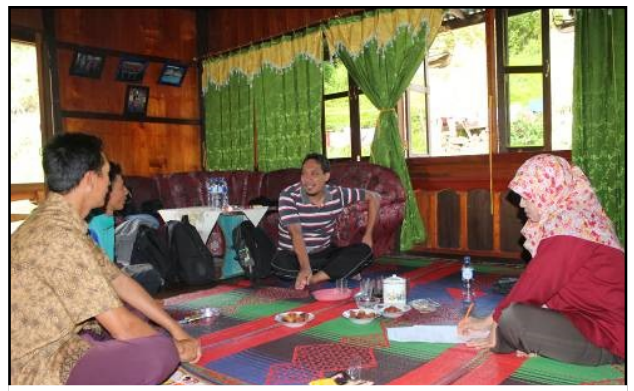

Fig. 6. Focus Group Discussion 
Involving stakeholders to conserve and cultivate non timber forest products (NTFP) in the research area means to support the sustainability of this forest product as one of natural resource. NTFP substantially contribute to rural livelihood strategies since it generates revenue for the communities and sustains forested landscape [12][13][14]. The existence of NTFP in the natural forest as public goods can cause commons dilemma because of overexploitation or degradation [1]. Therefore engaging related stakeholders to manage NTFPs sustainably is very crucial.

\subsubsection{Case study 2 - Paludiculture model based on silvopasture as an alternative of peatland restoration}

All related stakeholders have a desire to participate in this research program because peatland restoration is very important for the sustainability of natural resources in the research area, Ogan Komering Ilir, South Sumatra. Discussion with the representatives from ministry of agriculture at the district level was carried out to gather information about any programs that this institution applied (Fig. 7). Furthermore, some information and support from private company which operate in the research area was also needed, hence the discussion with this actor was also done (Fig. 8). Household interview (Fig. 9) and questionnaire method (Fig. 10) were important to gain data and information about household activity, support, and hopes in the future regarding peatland condition in their area. Finally farmers group meeting (Fig. 11) and focus group discussion (Fig. 12) was also conducted in order to gather information and support from group of people. It is very important to make sure that community activities in peatland area did not endanger the preservation of natural resources in this location.

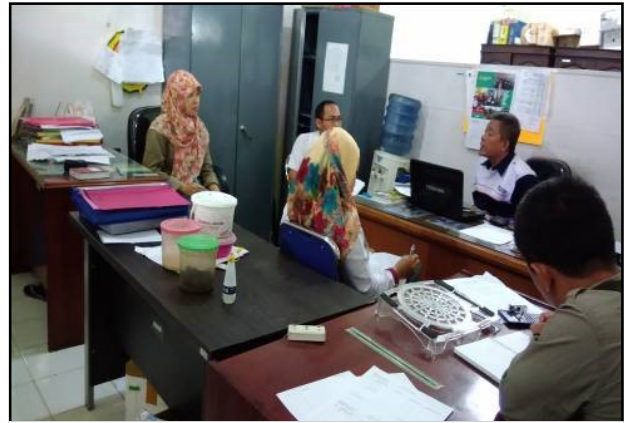

Fig. 7. Discussion with representatives from ministry of agriculture at the district level

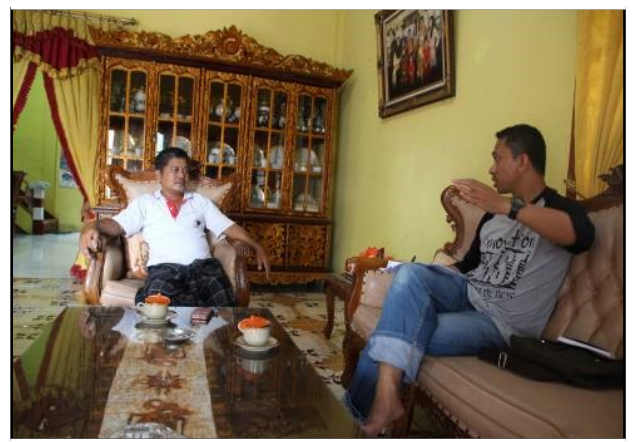

Fig. 9. Household interview

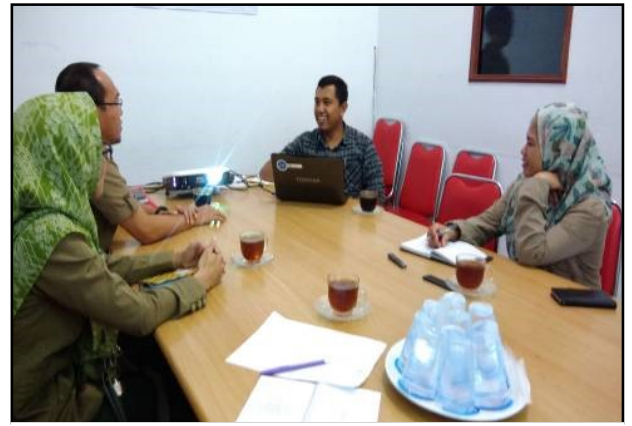

Fig. 8. Discussion with representatives from private company

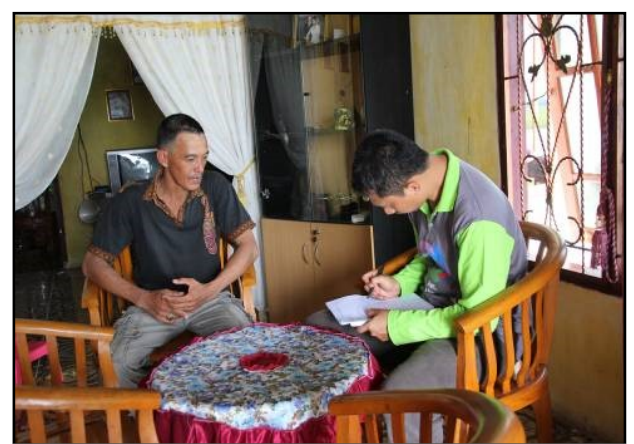

Fig. 10. Questionnaire method 


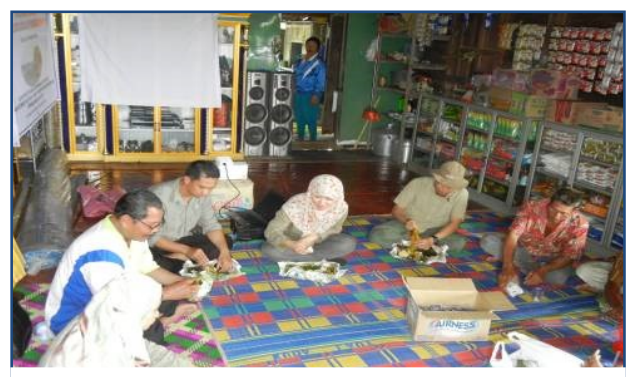

Fig. 11. Farmers group meeting

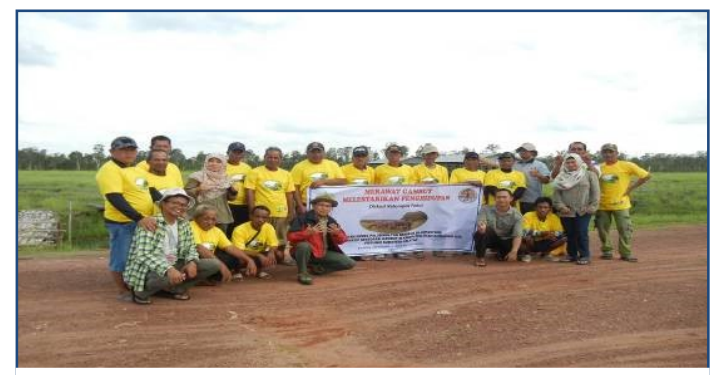

Fig. 12. Focus Group Discussion in the village level

\subsection{The importance of stakeholder engagement}

Stakeholder engagement is crucial to the success of sustainable natural resources manegement. Some research projects were carried out by various institutions, both government and private to ensure the sustainability of this resource. From the beginning, the project must have clear objectives and planning hence effective strategic could be applied during the research project. Stakeholders who engage in the program will have chance to express their opinion since at the end they will affect or affected by the outcomes of the program. The stakeholder could have greater clarity and shared ideas among them. Each stakeholder will understand the relationship between them and also to the program and the main goal of the research projects. Therefore, if it is beneficial for them or the environment nearby, those stakeholders will have great eagerness to participate in the research projects since natural resource is very importing to support their life.

The role of stakeholder engagement in a certain project depends on how powerful and how big is their interest to the projects. Eden and Ackermann [15] described stakeholder categories based on their power and interest (Fig. 13).

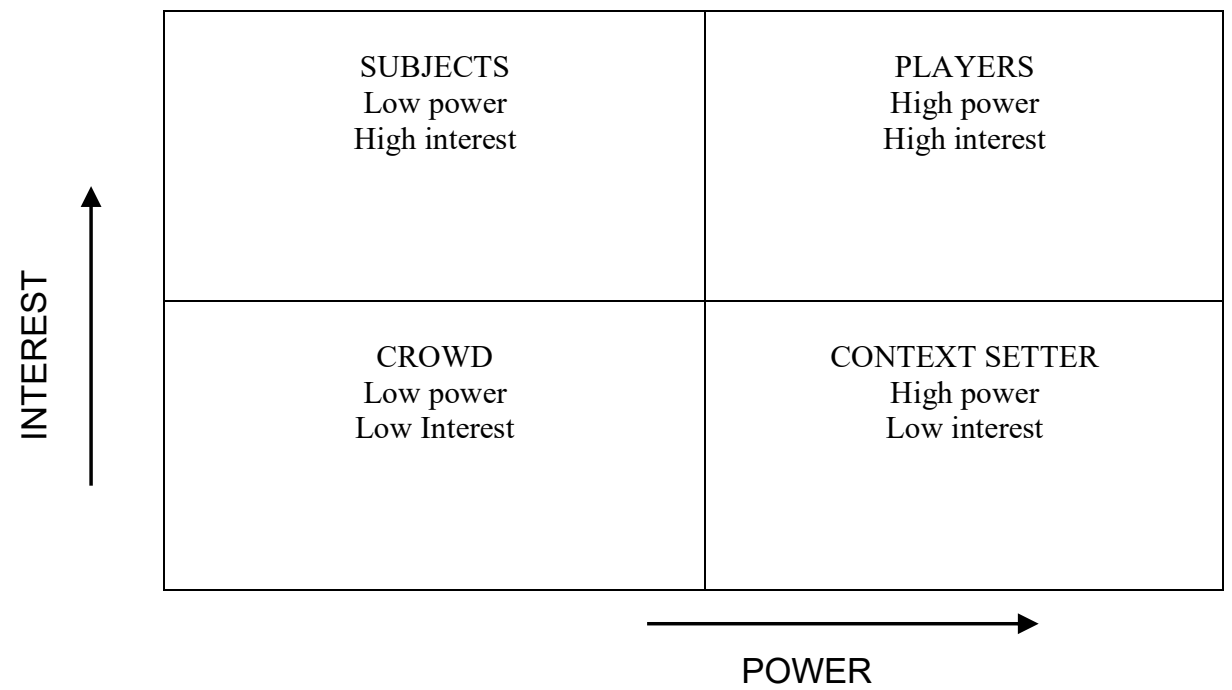

Fig. 13. Interest versus power of the stakeholders

Power versus interest graph could help in determining which stakeholders who have high interests and high power that must be recognized during the program [16]. Stakeholder in 
crowd area has low power and low interest in the research project, otherwise player has high power and also interest to the research project. Therefore we have to pay more attention to the player hence they have eagerness to involve in the project and support the project in gaining the goals that is sustainable natural resource management.

At the early stages of the planning process, various inputs, opinion and insights from stakeholders are very useful for the smooth process of the projects. This strategy will also help to translate stakeholder needs regarding the research project goals. Since people mainly engage in activity that address their needs [17]. Each stakeholder could take a part and role in the research project processes, hence the goals can be achieved easily according to the schedule in the planning. The involvement of stakeholder primary needed because in general, stakeholders have the knowledge, experience and expertise that are important to support the research project process to preserve natural resource. Stakeholder engagement will give several benefits [3][7][8][5][18]:

- Stakeholder engagement could enhance the quality of natural resources management since the information inputs will be more comprehensive.

- All the parties who will affect or affected by the outcome of the program would have opportunity to express their ideas.

- Identify who are the key stakeholders and understand the relationship between them and also to the program. Therefore, their role can be analyzed and represented systematically.

- Brings people together to share their knowledge, experience, and expertise to obtain the goals or solutions of the problems.

- Collaborative partnerships and new relationships that generate value could be developed hence the best strategies can be decided to gain the goals. Therefore the level of risk could be reduced and the governance could be improved

\subsection{Implementation Strategy in Increasing Stakeholder Engagement for Sustainable Natural Resource Management}

Stakeholder engagement becomes key factor in the successes of the project [19], including in the preserving natural resource program. In order to increase stakeholder engagement, providing clear information to them about the goals to be achieved in natural resource management activities is the first step that must be carried out. A detailed description of what stakeholders can do to participate is the next step. The third step is to convince stakeholders that they can participate easily and their role is very important in managing this natural resource. Updating information about what has been done, how the results are, and what things are still needed to do in order to reach the goal is the final step that must be completed.

Active discussion, consultation, and providing open forum discussion such as focus group discussion (FGD) become one of an effort of engagement process strategy. In the FGD process, each stakeholder could have interactive engagements between them. Moreover, they will have chance to share knowledge and ideas lead to greater ownership of the program hence they could achieved the common goals and give some input for best outputs. There are some strategies to develop stakeholder engagement:

a. Classify and define stakeholder power and interest (Fig. 13)

We have to define what the stakeholder interest in the project really is because their needs and want are important to make sure that the stakeholder would have eagerness to participate in the projects.

b. Develop the stakeholder engagement plan.

In order to engage stakeholder involvement, these activities could be applied: clear and consistent communication; All parties need to have a clear understanding of the process and the objectives. Information needs to be shared proporsionally and consistent during the 
projects. Stakeholder involved needs to have opportunity to exchange information, improve transparency [20] and understanding the vision between stakeholder; Outline the engagement that required from each stakeholders involved in the sustainable natural resource management.

Based on the process of stakeholder engagement in two socioeconomic research project, we found that there are some factors affecting stakeholder engagement: effective communication, hence the stakeholder will pay more attention and time about what is the project, the purposes and what kind of thing that they can do to support the support in managing natural resource sustainably. Another factor is that direct or indirect benefits that can be obtained by the stakeholders. The more the benefits that the stakeholder can get, their eagerness to participate in the research project would be higher. These benefits could be both tangible and intangible advantage. The last factor is that stakeholder involvement must be recognized as an integral part of the process in sustainable natural resource management. All stakeholders must be involved in the whole process hence they will knowledgeable more about the ongoing natural resource management projects and have strong desire to stay involved and participate until the project is completed and successfully achieves the goals.

\section{Conclusion}

Natural resources is experiencing degrade and dramatically decline both in the quantity quality and function. Face to face interactions and constructive discussions between stakeholders involved in natural resources management generate beneficial collaborative participatory mechanism during the ongoing projects. Our finding explained that in increasing stakeholder engagement, some steps could be taken. The fist step is providing clear information to the stakeholders about the goals to be achieved in natural resource management activities. The second is about a detailed description of what stakeholders can do to participate. Moreover, convincing the stakeholders that they can participate easily and their role is very important in managing this natural resource. The last step is updating information about what has been done, how the results are, and what things are still needed to do in order to reach the goal. Stakeholders will actively participate in natural resource management activities if they know clearly the objectives to be achieved, one of these objectives must be directly or indirectly related to the interests of these stakeholders and provide benefits both material and or non-material to them. There are some factors affecting stakeholder engagement, among others are effective communication, direct or indirect benefits that can be obtained by the stakeholders, stakeholder involvement must be recognized as an integral part of the process in sustainable natural resource management. All stakeholders must be involved in the whole process of natural resource management hence they will knowledgeable more about the ongoing projects and have strong desire to stay involved and participate

\section{Acknowledgement}

We would like to express our deep gratitude to the Environment and Forestry Research Development Institute of Palembang for the support. 


\section{References}

1. Feeny D, Berkes F, McCay B J and Acheson, James M 1990, Hum. Ecol. 18 1-19

2. Gardner R O Y, Ostrom E and Walker J M, The nature of common-pool resource problems Ration. Soc. 2 335-58 (1990)

3. Reed M S, Biol. Conserv. 141 2417-31 (2008)

4. Allen W and Kilvington M 2010 Stakeholder analysis Hatched: The capacity for sustainable development ed B Frame, R Gordon and C Mortimer (Publication (SD)) pp 249-54

5. Haddaway N R, Kohl C, Silva N R, Schiemann J, Spök A, Stewart R, Sweet J B and Wilhelm R, Environ. Evid (2007)

6. Deverka P A, Lavallee D C, Desai P J, Esmail L C and Scott D 2013 J Comp Eff Res 1 181-94 (2013)

7. Talley J L, Schneider J and Lindquist E, Ecology and Soiety 21, 4(2016)

8. Cottrell E K, Whitlock E P, Kato E, Uhl S, Belinson S, Chang C, Hoomans T, Meltzer D O, Noorani H, Robinson K A, Anderson J and Paynter R A, Agency for Healthcare Research and Quality 13-9 (2014)

9. Wichtmann W and Joosten H 2007 Paludiculture: Peat formation and renewable resources from rewetted peatlands The depiction of mires and other wetlands by ancient cultures View project soil carbon View project

10. Orefice J, Carroll J, Conroy D and Ketner L, Agrofor. Syst. 91 149-60 (2007)

11. Flannery W and Cinnéide M Ó Society \& Natural Resources 37-41 (2012)

12. Laird S A, Wynberg R and Mclain R J, Regulating Complexity 227-53 (2011)

13. Ghosal S, Journal of Geography and Regional Planning 4 159-68 (2011)

14. Ros-tonen, Mirjam A F K F W, AGIDS, 130 (2003)

15. Ackermann F and Eden C, Long Range Plann. 44 179-96 (2011)

16. Bryson J M, Minneapolis (2004)

17. Galabuzi C, Eilu G, Mulugo L, Kakudidi E, Robert J and Tabuti S, Springer, 13 (2013)

18. Sterling E J, Betley E, Sigouin A, Gomez A, Toomey A, Cullman G, Malone C, Pekor A, Arengo F, Blair M, Filardi C, Landrigan K and Luz A, Biol. Conserv. 209 159-71 (2007)

19. Talley J L, Schneider J and Lindquist E, Ecology and Society 21, 4 (2016)

20. Kenney L, Arvai J, Vardhan M and Catacutan D, Soc. Nat. Resour. 28 261-79 (2015) 